\title{
Radiopathological Features and Identification of Mycobacterial Infections in Granulomatous Nodules Resected from the Lung
}

\author{
Yumi Sakakibara $^{a}$ Yoshimi Suzuki ${ }^{b}$ Toshihide Fujie ${ }^{a}$ Takumi Akashic \\ Tadatsune lida $^{d}$ Yasunari Miyazaki $^{a}$ Yoshinobu Eishi ${ }^{b}$ Naohiko Inase ${ }^{a}$ \\ ${ }^{a}$ Department of Respiratory Medicine, ${ }^{b}$ Department of Human Pathology, and ${ }^{c}$ Division of Surgical Pathology, \\ Tokyo Medical and Dental University, and ${ }^{\mathrm{d}}$ Department of Cellular Neurobiology, Tokyo University, Tokyo, Japan
}

\section{Keywords}

Granuloma $\cdot{ }^{18}$ Fluorine-fluorodeoxyglucose positron emission tomography - Mycobacterial infection .

Formalin-fixed and paraffin-embedded tissue specimens . IS6110

\section{Abstract}

Background: Pulmonary granulomas are sometimes resected because they resemble lung cancer and false-positive findings come through from positron emission tomography (PET) using ${ }^{18}$ fluorine-fluorodeoxyglucose $\left({ }^{18} \mathrm{~F}-\mathrm{FDG}\right)$. Mycobacterial infection is a common cause of granulomas. Objective: The purpose of this study was to evaluate the radiopathological features and the methods for identifying mycobacterial infections in granulomatous nodules resected from the lung. Methods: Thirty-five solitary lesions resected because of suspected lung cancer were enrolled, including 22 nonfungal granulomatous lesions and 13 benign lesions as controls. The radiological, microbiological, and histological findings were reviewed. To identify mycobacterial infection, immunohistochemical (IHC) staining, IS6110 polymerase chain reaction $(\mathrm{PCR})$, and real-time $\mathrm{PCR}$ for the detection of Mycobacterium tuberculosis (TB) were performed using formalin-fixed and paraffin-embedded tissue specimens. The correlations between the radiopathological features and the median maximum standardized uptake value $\left(S U V_{\max }\right)$ of ${ }^{18}$ F-FDG PET were also evaluated. Results: Mycobacteria were isolated from the cultures of 10 of the granulomatous lesions, including TB from 2 and Mycobacterium avium complex from 8. The mean size of the nodules in the culture-positive group was significantly larger than that of those in the culture-negative group $(30.5 \pm 13.1$ vs. $15.1 \pm 6.3 \mathrm{~mm}, p=$ 0.003). IHC stainings were positive in 15 granulomas. Eight granulomas were positive in $1 S 6110 \mathrm{PCR}$, and 7 of them were also positive in real-time PCR. SUV $\max$ was $\geq 2.5$ in all of the PCR-positive granulomas. Conclusion: The most frequent cause of granulomatous lesions was mycobacterial infection. It seemed that the culture result was associated with nodule size and that the results of IS6110 were associated with ${ }^{18} \mathrm{~F}$-FDG-uptake.

(c) 2017 S. Karger AG, Basel

\section{Introduction}

Chest X-rays and computed tomography (CT) scans of pulmonary granulomas may sometimes show solitary nodules with spicula formation and/or pleural indentation, features suggestive of lung cancer. Positron emis-

\section{KARGER}

(c) 2017 S. Karger AG, Basel

E-Mail karger@karger.com

www.karger.com/res
Yasunari Miyazaki, MD, $\mathrm{PhD}$

Department of Respiratory Medicine

Tokyo Medical and Dental University

1-5-45, Yushima, Bunkyo-ku, Tokyo 113-8519 (Japan)

E-Mail miyazaki.pilm@tmd.ac.jp 


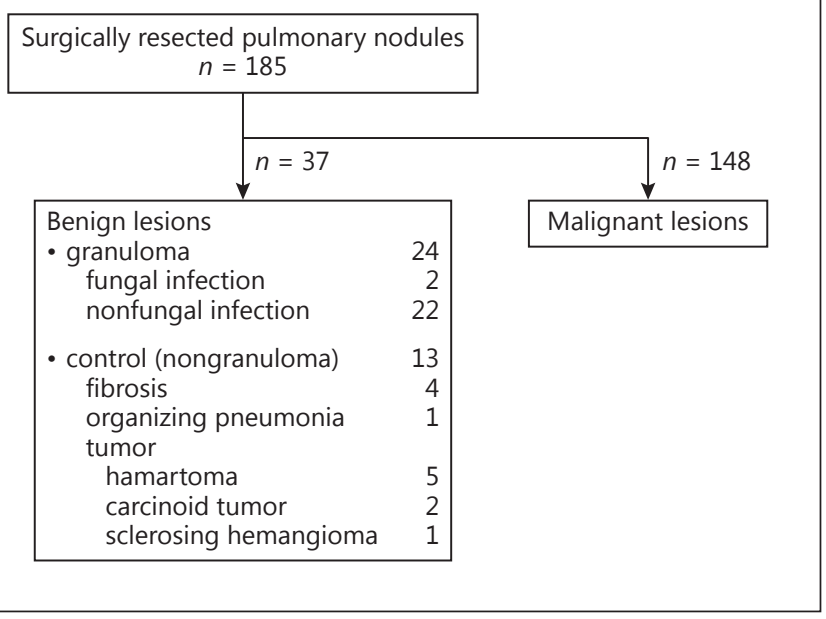

Fig. 1. Flow diagram of case selection.

sion tomography (PET) using ${ }^{18}$ fluorine-fluorodeoxyglucose $\left({ }^{18} \mathrm{~F}-\mathrm{FDG}\right)$, meanwhile, can return false-positive results in the assessment of pulmonary granulomas $[1,2]$. For these reasons, pulmonary granulomas are often resected as suspected lung cancers. The major causes of granuloma are sarcoidosis and mycobacterial or fungal infections $[3,4]$. While fungus (Histoplasma or Coccidioides) is more commonly identified than mycobacteria in the United States, mycobacterial infection is the most common cause of pulmonary granuloma in the rest of the world [5].

Acid-fast bacilli (AFB) cultures provide important information for identifying mycobacteria, but cultures of resected specimens have low sensitivity. Ziehl-Neelsen (ZN) staining has a similarly low sensitivity and fails to distinguish among mycobacterial species. Immunohistochemical (IHC) staining with anti-BCG polyclonal antibody $(\mathrm{pAb})$ is a well-recognized method for detecting mycobacterial antigen. IHC staining with anti-lipoarabinomannan (LAM) monoclonal antibody ( $\mathrm{mAb}$ ) shows a high sensitivity in old tuberculous lesions [6]. Even after microbiological and pathological analysis, $25-41 \%$ of granulomas remain undiagnosed $[4,5]$.

Moderate to high rates of mycobacterial infection commonly lead to mycobacterial granulomas. Japan remains a medium-burden tuberculosis country, with a tuberculosis incidence rate of 18 cases per 100,000 population according to the World Health Organization report in 2014 [7]. Compared with Europe and the United States, the latest reports from Japan also reveal a steady increase in the prevalence of nontuberculous mycobacteria (NTM) and the number of surgical resections for pulmonary disease [8-10]. It has thus become important to distinguish Mycobacterium tuberculosis (TB) from NTM for postoperative management, especially in patients with TB.

While the correlation between the median maximum standardized uptake value $\left(\mathrm{SUV}_{\max }\right)$ for ${ }^{18} \mathrm{~F}-\mathrm{FDG}$ and mycobacterial species remains controversial, increased ${ }^{18} \mathrm{~F}-\mathrm{FDG}$ uptake is associated with mycobacterial activity and reflects hypoxia $[2,11-14]$. Few reports, however, have evaluated how $S_{\text {UV }}$ correlates with histological features or the results of mycobacterial identification [12].

In the present study, we evaluated the radiopathological features of mycobacterial infections in granulomas suspected to be lung cancers, the methods used to identify the infections, and the correlations with $\mathrm{SUV}_{\max }$.

\section{Materials and Methods}

This study is a retrospective analysis approved by the ethics committee of Tokyo Medical and Dental University, Tokyo, Japan (approval number 2295). We collected 185 solitary pulmonary nodules surgically resected as suspected lung cancers at Tokyo Medical and Dental University Hospital between January 2010 and March 2015. Nodules preoperatively diagnosed as lung cancer were excluded. Therefore, these nodules were resected owing to the physician's decision by clinical and radiological features.

In total, $148(80 \%)$ of the 185 nodules were malignant lesions, $24(13 \%)$ were granulomas, and $13(7 \%)$ were benign lesions of other types (Fig. 1). Two of the 24 granulomas were histologically diagnosed as fungal infections. For this study, the 22 nonfungal granulomas and the 13 benign lesions were enrolled as the granuloma and the control group, respectively. Figure 1 shows the pathological diagnoses of the controls. The clinical and pathological data collected from electronic records were analyzed.

Chest CT scans were available for all patients. The most recent scans before operation were evaluated. ${ }^{18}$ F-FDG PET images obtained in the 6 months before the resections were included. Cases with elevated blood sugar levels known to compromise the reliability of the $\operatorname{SUV}_{\max }\left(>150 \mathrm{mg} / \mathrm{dl}\right.$ ) were excluded. $\mathrm{SUV}_{\max }$ estimations for the nodules using the traditionally reported cutoff value of 2.5 revealed associations with microbiological, histological, and microbiological genetic findings [1]. The microbiological data were confirmed from the resected lesions and/or transbronchial washings using standard laboratory procedures.

Formalin-fixed and paraffin-embedded (FFPE) tissue specimens were collected and the largest lesion in each specimen was analyzed. After deparaffinization, 3- $\mu \mathrm{m}$-thick sections of tissue were treated by hematoxylin and eosin staining followed by Grocott, acid-fast (ZN), and IHC staining for mycobacteria (anti-LAM $\mathrm{mAb}$, anti-BCG pAb) by the methods described by Iida et al. [6].

The lesions in each section were resected manually by microtome. DNA was extracted from three $6-\mu \mathrm{m}$ tissue slices according to previously reported protocols using QIAamp DNA kits (Qia- 
Table 1. Patient characteristics

\begin{tabular}{|c|c|c|c|}
\hline & $\begin{array}{l}\text { Granuloma } \\
(n=22)\end{array}$ & $\begin{array}{l}\text { Control } \\
(n=13)\end{array}$ & $p$ \\
\hline Age, years & $66.3 \pm 10.3$ & $62.7 \pm 8.4$ & 0.29 \\
\hline \multicolumn{4}{|l|}{ Gender } \\
\hline Male & $9(41 \%)$ & $9(69 \%)$ & \multirow[t]{2}{*}{0.11} \\
\hline Female & $13(59 \%)$ & $4(31 \%)$ & \\
\hline BMI & $22.8 \pm 2.1$ & $23.4 \pm 2.9$ & 0.6 \\
\hline \multicolumn{4}{|l|}{ Smoking history } \\
\hline Never smokers & $11(50 \%)$ & $4(31 \%)$ & \multirow[t]{3}{*}{0.53} \\
\hline Ex smokers & $10(46 \%)$ & $8(62 \%)$ & \\
\hline Current smokers & $1(5 \%)$ & $1(8 \%)$ & \\
\hline \multicolumn{4}{|l|}{ Underlying pulmonary disease } \\
\hline Previous tuberculosis & $2(9 \%)$ & $0(0 \%)$ & 0.26 \\
\hline COPD & $2(9 \%)$ & $1(8 \%)$ & 0.89 \\
\hline Interstitial pneumonia & $1(5 \%)$ & $0(0 \%)$ & 0.44 \\
\hline Bronchial asthma & $0(0 \%)$ & $1(8 \%)$ & 0.19 \\
\hline Post lung cancer & $1(5 \%)$ & $0(0 \%)$ & 0.44 \\
\hline \multicolumn{4}{|l|}{ Location } \\
\hline RUL/RML/RLL/LUL/LLL & $7 / 6 / 3 / 2 / 4$ & $6 / 2 / 1 / 3 / 1$ & 0.56 \\
\hline Size, $\mathrm{mm}$ & $22.8 \pm 12.8$ & $18.6 \pm 10.6$ & 0.31 \\
\hline \multicolumn{4}{|l|}{ CT findings } \\
\hline Cavity & $1(5 \%)$ & $0(0 \%)$ & 0.44 \\
\hline Calcification & $6(27 \%)$ & $3(23 \%)$ & 0.78 \\
\hline Indentation & $16(73 \%)$ & $5(39 \%)$ & 0.05 \\
\hline Consolidation around nodule & $11(50 \%)$ & $3(23 \%)$ & 0.16 \\
\hline Bronchiectasis & $5(23 \%)$ & $1(8 \%)$ & 0.25 \\
\hline Peripheral location & $17(77 \%)$ & $4(31 \%)$ & 0.01 \\
\hline Size diminished before resection & $8(36 \%)$ & $1(8 \%)$ & 0.06 \\
\hline \multicolumn{4}{|l|}{${ }^{18} \mathrm{~F}-\mathrm{FDG}$ PET } \\
\hline Patients undergoing ${ }^{18} \mathrm{~F}$-FDG PET & 19 & 11 & \\
\hline $\mathrm{SUV}_{\max }$ & $3.7 \pm 2.5$ & $1.0 \pm 1.0$ & $<0.05$ \\
\hline $\mathrm{SUV}_{\max } \geq 2.5$ & $12(63 \%)$ & $1(9 \%)$ & $<0.05$ \\
\hline
\end{tabular}

Values are presented as mean \pm SD or $n(\%)$. BMI, body mass index; COPD, chronic obstructive pulmonary disease; LLL, left lower lobe; LUL, left upper lobe; RLL, right lower lobe; RML, right middle lobe; RUL, right upper lobe.

gen, Valencia, CA, USA) [6]. The solution obtained was assessed by nested polymerase chain reaction (PCR) and real-time PCR for TB. The PCR was performed to amplify the TB complex-specific insertion sequence with 123-bp lengths using the primer combination of IS6110 previously described by others [15]. The amplified product was visualized under ultraviolet light after electrophoresis on 3\% agarose gels containing ethidium bromide. Extraction DNA was purified with a GENE CLEAN II kit (MP biomedicals, Santa Ana, CA, USA). Primers for real-time PCR quantification were used to amplify the IS6110. Primers MT-F (5'-TCG ACG CGA TCG AGC AA- $\left.3^{\prime}\right)$ and MT-R (5'-GGA TAA CGT CTT TCA GGT CGA GTA C-3') were designed to amplify $69 \mathrm{bp}$. The probe sequence was $5^{\prime}$-CCA TCT GGA CCC GCC AAC AAG AAG-3'. A variation of the real-time PCR method described by Iida et al. [6] was performed using an ABI PRIZM 7900HT Sequence Detection System (Applied Biosystems, Foster City, CA, USA) with standard samples of serially diluted bacterial DNA. Finally, the result of quantitative PCR for each sample was expressed as the number of bacterial genomes in DNA from the sample. A level of $>1$ copy was judged to be a positive result. Assays were performed twice per triple well for each sample and the mean number of genomes was calculated.

Statistical differences were evaluated using the Mann-Whitney $\mathrm{U}$ test. A $p$ value $<0.05$ was considered statistically significant. Analyses were performed using GraphPad PRISM version 5.0a (GraphPad Software, Inc., USA).

\section{Results}

Table 1 summarizes the clinical characteristics of the 22 patients with granulomas (granuloma group) and the 13 patients with benign lesions (control group). The granuloma group consisted of 9 men and 13 women (mean age, $66.3 \pm 10.3$ years; range, $45-84$ years), the control group of 9 men and 4 women (mean age, $62.7 \pm 8.4$ years; range, 45-73 years). Eleven patients in the granuloma group and 4 in the control group were never smokers. Two patients (9\%) in the granuloma group had histories of previous tuberculosis, but no patients had histories of immunosuppression or clinical diagnoses of sarcoidosis, rheumatoid arthritis, other variants of arteritis, or human immunodeficiency virus infection. No differences in clinical characteristics were observed between the groups.

The mean nodule size on CT was $22.8 \pm 12.8 \mathrm{~mm}$ in the granuloma group and $18.6 \pm 10.6 \mathrm{~mm}$ in the controls (Table 1). The locations and sizes of the nodules were not significantly different between the groups, although a peripheral location was more prevalent in the granuloma patients. While nodule growth consistent with lung cancer was observed in 15 granulomas over the clinical course, chest CT scans before the operations revealed spontaneous diminishment of nodule size in 8 cases. ${ }^{18} \mathrm{~F}$ FDG PET imaging data were available for 19 patients in the granuloma group and 11 controls. The median $\mathrm{SUV}_{\text {max }}$ was significantly higher in the granuloma group than in the controls $(3.7 \pm 2.5$ vs. $1.0 \pm 1.0, p<0.05)$. Twelve cases $(63 \%)$ in the granuloma group were positive on SUV max $_{\text {. }}$

AFB cultures performed on 18 cases were positive in 10 cases ( 2 for TB and 8 for Mycobacterium avium complex [MAC]) and negative in 8 (Table 2). All but 1 of the positive cultures were from surgical specimens. The culture came back negative in 1 surgical specimen, but MAC was detected in a bacterial culture of bronchial washing fluid obtained from the same patient before the operation (case 10 in Table 2).

The mean nodule size was significantly larger in the culture-positive group than in the culture-negative group $(30.5 \pm 13.1$ vs. $15.1 \pm 6.3 \mathrm{~mm}, p=0.003)$ (Fig. 2$)$. No cor- 


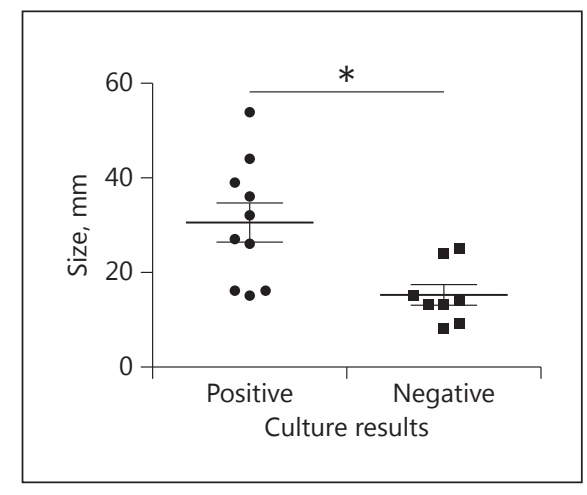

Fig. 2. The nodule size in the culture-positive and -negative groups. $* p=0.003$.

relation was noted, however, between $S U V_{\text {max }}$ and nodule size $(r<0.1, p=1.0)$. The mean $\mathrm{SUV}_{\max }$ was $4.0 \pm 0.7$ in the culture-positive group (TB, $4.2 \pm 2.4$; MAC, $3.9 \pm 2.2$ ) and $3.4 \pm 1.6$ in the culture-negative group $(p=0.72)$.

All of the 22 nodules had the histologic features of epithelioid cell granuloma, and 12 were found to be small, confluence-positive granulomas (Table 2). Sixteen of the nodules had caseous necrosis. Calcification was observed in 2 nodules resected from patients with a history of previous TB (cases 9 and 22 in Table 2). Neutrophil infiltration was observed in 5 granulomas, exudative reaction in 14 , fibrosis in 17 , and bronchiectasis in 8 .

Grocott staining was negative in all of the samples. Anti-LAM mAb staining and anti-BCG pAb staining were positive in $15(68 \%)$ and $12(55 \%)$ cases, respectively. The anti-LAM $\mathrm{mAb}$ staining was focal, whereas the anti-BCG $\mathrm{pAb}$ staining was diffuse. The IHC staining was more positive in the necrotizing zone and in the periphery of the granulomas than elsewhere. Both antibodies failed to distinguish TB from MAC (Fig. 3). ZN staining was positive in only 3 cases (14\%) (Table 2 ). In contrast, the mycobacterial stainings were negative in all of the control lesions.

Confluence-positive epithelioid cell granuloma and caseous necrosis were both correlated with $\mathrm{SUV}_{\max }$ (confluence-positive $4.9 \pm 0.8$ vs. confluence-negative $2.4 \pm$ $1.5, p=0.034$; caseous necrosis-positive $4.5 \pm 2.7$ vs. caseous necrosis-negative $2.1 \pm 1.0, p=0.039$ ). $\mathrm{SUV}_{\max }$ was higher in the granulomas with severe caseous necrosis. $\mathrm{SUV}_{\max }$ and the intensity of IHC staining were uncorrelated.

Eight cases (36\%) with granuloma were positive for IS6110 by nested PCR, and 7 of these 8 cases (32\%) were also positive by real-time PCR. There were no cases whose

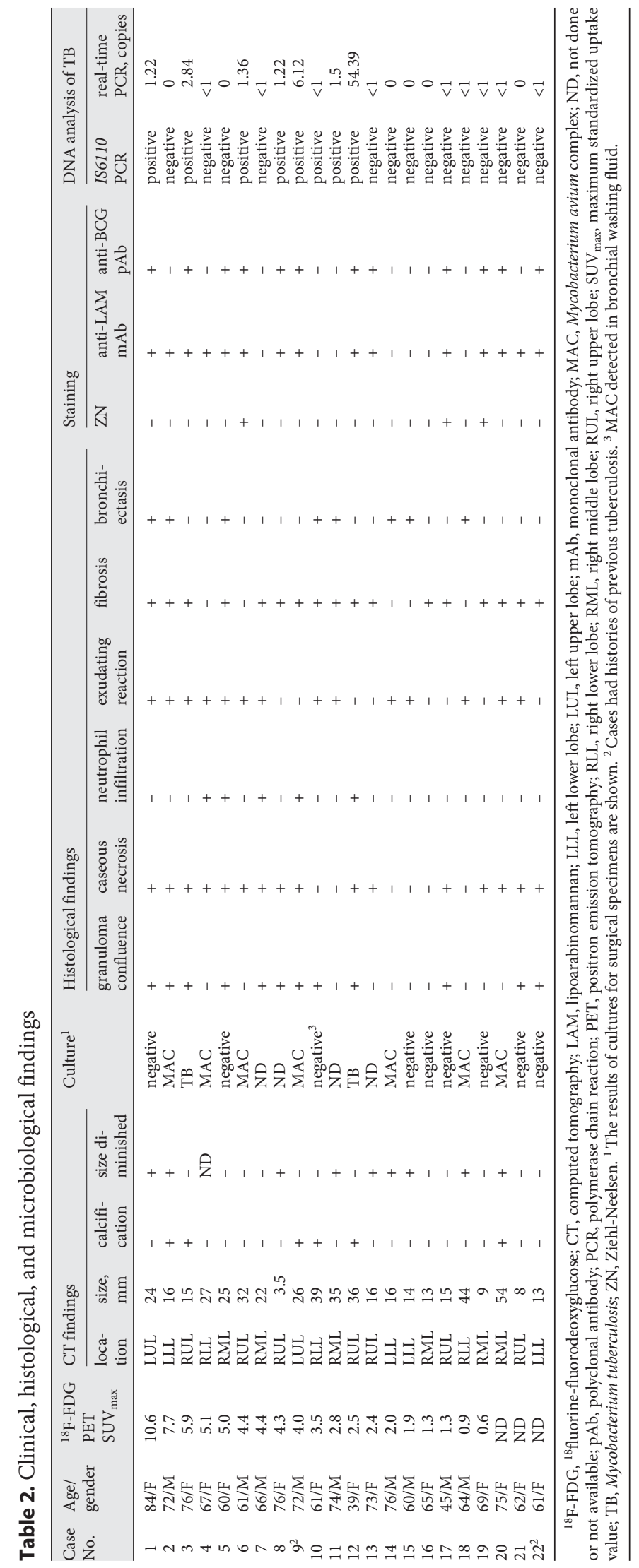

Respiration 2017;93:264-270 DOI: $10.1159 / 000456550$ 
Fig. 3. Radiological and histological findings in granulomas of Mycobacterium avium complex (case 2, a-c), of unknown etiology (case 8, d-f), and Mycobacterium tuberculosis (TB) (case 12, $\mathbf{g - i}$ ) by culture result. Positron emission tomographycomputed tomography images show solitary pulmonary nodules with high uptake of ${ }^{18}$ fluorine-fluorodeoxyglucose (a, d, g). Granulomas with caseous necrosis did not observably differ among species (b, e, h; original magnification $\times 100)$. Anti-lipoarabinomannan monoclonal antibody reacted in epithelioid cell granuloma, especially within the caseous necrosis of a case with $\mathrm{TB}(\mathbf{c}, \mathbf{f}$, i; original magnification $\times 1,000)$.
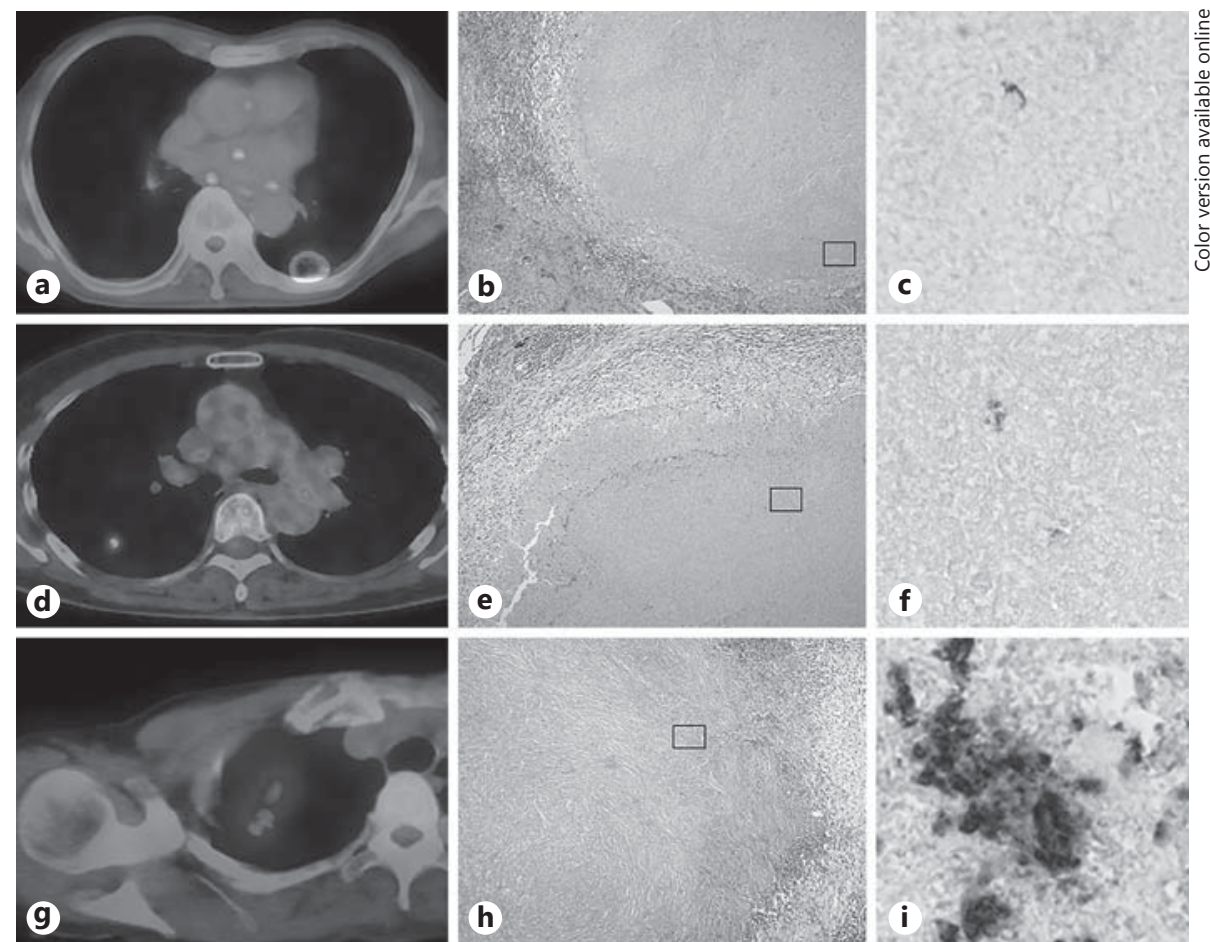

result of real-time PCR was solely positive. All of the control lesions were negative by both methods. $\mathrm{SUV}_{\max }$ was $\geq 2.5$ in all of IS6110 PCR- and real-time PCR-positive cases (Table 3). Granuloma size and positivity on IS6110 PCR/real-time PCR were uncorrelated (data not shown).

\section{Discussion}

Mycobacterial infection (86\%) was the most frequent cause of nonfungal granulomas in our study. AFB culture was diagnostic of nearly half of our granuloma cases, while IHC staining had the highest sensitivity.

Previous reports have proposed that any solitary pulmonary nodule exceeding 8 or $10 \mathrm{~mm}$ in diameter and manifesting a high uptake of ${ }^{18} \mathrm{~F}$-FDG should be resected for diagnosis in consideration of lung cancer $[16,17] .{ }^{18} \mathrm{~F}$ FDG PET may give false-positive results (10-25\%) in many infectious and inflammatory diseases containing active macrophages, especially granulomatous diseases [2]. While $63 \%$ of our granulomas had high ${ }^{18}$ F-FDG uptake, none exhibited the correlation between $\mathrm{SUV}_{\max }$ and nodule size normally observed in cancer. The absence of this correlation might be attributable to differences between infectious disease and cancer. A sustained ${ }^{18} \mathrm{~F}$-FDG uptake in cancer is associated with tumor development,
Table 3. Comparison between the results of IS6110 PCR for Mycobacterium tuberculosis and the $\mathrm{SUV}_{\max }$ value on ${ }^{18} \mathrm{~F}-\mathrm{FDG}$ PET

\begin{tabular}{lll}
\hline $\begin{array}{l}\text { IS6110 PCR for } \\
\text { Mycobacterium tuberculosis }\end{array}$ & $\mathrm{SUV}_{\max }$ \\
\cline { 2 - 3 } & $\geq 2.5(n=12)$ & $<2.5(n=7)$ \\
\hline Positive & 8 & 0 \\
Negative & 4 & 7 \\
\hline
\end{tabular}

${ }^{18} \mathrm{~F}-\mathrm{FDG},{ }^{18}$ fluorine-fluorodeoxyglucose; PCR, polymerase chain reaction; $\mathrm{PET}$, positron emission tomography; $\mathrm{SUV}_{\max }$, maximum standardized uptake value.

and the uptake steadily increases. In contrast, the inflammatory cells of infected tissue have a glucose hypermetabolism and gradually decrease as the tissue heals [18].

Cultures are more likely to detect mycobacteria than histology, whereas histological methods can easily detect fungi $[3,4]$. The diagnosis of mycobacterial infection from the results of AFB culture is regarded as the gold standard. Microbiological examination of resected nodules to identify mycobacterial species is therefore crucially important during the operation. When the pulmonary nodules in our study exceeded $25 \mathrm{~mm}$, the culture results were likely 
to come back positive (Fig. 2). This link between nodule size and positive culture suggests that resected tissue from larger nodules might be diagnosable by culture.

$\mathrm{ZN}$ staining is the routine examination for the detection of mycobacteria in FFPE sections, but the damage exacted by the formalin and xylene reduces the sensitivity of the assessment [19]. IHC staining is the most reliable method. Anti-LAM mAb, a method capable of staining one of the cell wall components of mycobacteria, proved to be useful for detecting localized NTM as well as TB in the present study. Anti-LAM mAb also provided clearer stains than anti-BCG pAb because of the $\mathrm{mAb}$.

While mycobacteria are typically identified by culture and conventional PCR from surgical samples, they can also be diagnosed genetically by nested PCR and realtime PCR with FFPE sections [20-23]. One-third of the granulomas in our study were positive in nested PCR and real-time PCR of IS6110, and 25\% of those with unknown etiologies could be diagnosed. According to Kim et al. [24], nested PCR and real-time PCR had sensitivities of 70.1 and $70.8 \%$, respectively, for detecting TB. The detection rates by both methods in our study were lower than those of previous reports [20,24]. The amounts of bacteria in our samples may have been too low to detect. Nodule-type lesions have been reported to contain fewer mycobacteria than cavitary or consolidation lesions [25]. According to previous reports, nested PCR and real-time PCR for TB or NTM had significantly higher positivity on specimens with positive AFB staining, caseous necrosis, and calcified lesions [4, 6, 24-27]. The selection of samples based on these points might be important. In our present study, SUV $\max$ was correlated with small confluent granulomas, caseous necrosis, and detectable IS6110. The evaluation of IS6110 might thus be useful for nodules with high $S \mathrm{SV}_{\max }$.

In our study, calcification on chest CT scans was detected in 6 cases, but could not be observed in the pathological findings of 5 of them. This may be due to the fact that we analyzed not the whole specimen, but the largest slice in each specimen. In addition, calcification was difficult to detect on CT scan because of the trivial size of the calcification on the specimen in case 22 (Table 2).

We found discrepancies between the culture results and detection of IS6110 in 3 cases clinically diagnosed as MAC infections: cases 6, 9, and 10. Case 10 was diagnosed following a culture of transbronchial washing fluid, and hence might have been colonized by MAC. Case 9 had a history of previous TB and showed calcification on CT, but the discrepancy remained inexplicable in case 6. Pulmonary MAC infection is often superimposed over pre-

Mycobacterial Diagnosis in Granuloma existing lung disease, especially previous tuberculosis [28]. A genetic analysis for mycobacterial infections in Taiwan revealed a number of NTM cases with previous TB [29]. Some TB-infected patients might go unrecognized in endemic areas. We should be mindful that active and/or inactive infection with TB can coexist with NTM in granulomas.

The distinction between TB and NTM has an important bearing on decisions regarding postoperative therapy. Sequencing of hsp65 with a short amplicon length obtained by nested PCR is useful for defining almost all mycobacterium species in FFPE sections. When we attempted to analyze $h s p 65$ sequencing according to previous publications [15, 29, 30], Mycobacterium gordonae was identified together with TB or MAC in the same samples. This result might indicate contamination.

Several limitations of the present study should be considered. First, the samples were insufficient to evaluate the species in further detail. This was unsurprising, as only granulomas undiagnosed before operation were enrolled. While previous reports have included biopsy specimens to collect samples in sufficient numbers, this approach would not have fit our purpose. Second, we were unable to evaluate the NTM species by DNA analysis. NTM with a short amplicon length are frequently difficult to identify, given the very close similarity between the genetic sequences of different NTM species. Further, NTM species such as MAC and M. gordonae prevail in experimental environments. Several factors contribute to sample contamination in the various stages of an experiment. As such, the mere detection of NTM does not implicate NTM as the sole causative organism. The diagnosis should be based on the results of several laboratory and clinical data.

In conclusion, the most frequent cause of pulmonary nodules with nonfungal granulomas was mycobacterial infection. Intensive mycobacterial examination should be seen as an imperative measure in countries with high or moderate prevalence. The methods we used to identify mycobacteria identification differed in several respects: it seemed that the culture result was associated with nodule size and that the results of IS6110 PCR/real-time PCR were associated with ${ }^{18} \mathrm{~F}$-FDG uptake.

\section{Acknowledgment}

The authors thank Keisuke Uchida and Asuka Furukawa from the Department of Human Pathology, Tokyo Medical and Dental University, for technical assistance, Kenichi Ohkubo and Hironori Ishibashi from the Department of Thoracic Surgery, Tokyo 
Medical and Dental University, for sample collection, and Akira Toriihara from the Department of Radiology, Tokyo Medical and Dental University, for valuable comments on ${ }^{18} \mathrm{~F}$-FDG PET.

\section{Financial Disclosure and Conflicts of Interest}

The authors declare that they have no conflicts of interest.

\section{References}

1 Sim YT, Goh YG, Dempsey MF, Han S, Poon FW: PET-CT evaluation of solitary pulmonary nodules: correlation with maximum standardized uptake value and pathology. Lung 2013;191:625-632.

2 Yilmaz F, Tastekin G: Sensitivity of ${ }^{18}$ F-FDG PET in evaluation of solitary pulmonary nodules. Int J Clin Exp Med 2015;8:45-51.

3 Mukhopadhyay S, Wilcox BE, Myers JL, Bryant SC, Buckwalter SP, Wengenack NL, Yi ES, Aughenbaugh GL, Specks U, Aubry MC: Pulmonary necrotizing granulomas of unknown cause: clinical and pathologic analysis of 131 patients with completely resected nodules. Chest 2013;144:813-824.

4 El-Zammar OA, Katzenstein AL: Pathological diagnosis of granulomatous lung disease: a review. Histopathology 2007;50:289-310.

5 Mukhopadhyay S, Farver CF, Vaszar LT, Dempsey OJ, Popper HH, Mani H, Capelozzi VL, Fukuoka J, Kerr KM, Zeren EH, Iyer VK, Tanaka T, Narde I, Nomikos A, Gumurdulu D, Arava S, Zander DS, Tazelaar HD: Causes of pulmonary granulomas: a retrospective study of 500 cases from seven countries. J Clin Pathol 2012;65:51-57.

6 Iida T, Uchida K, Lokman N, Furukawa A Suzuki Y, Kumasaka T, Takemura T, Kawachi $\mathrm{H}$, Akashi T, Eishi E: Calcified granulomatous lung lesions contain abundant Mycobacterium tuberculosis components. J Mycobac Dis 2013;4:142.

7 World Health Organization: Tuberculosis profile of Japan in 2014. http://www.who.int/ tb/country/data/profiles/en/ (accessed June 22, 2016)

8 Morimoto K, Hasegawa N, Izumi K, Namkoong $\mathrm{H}$, Uchimura K, Yoshiyama T, Hoshino Y, Kurashima A, Sokunaga J, Shibuya S, Shimojima M, Ato M, Mitarai S: A laboratory-based analysis of nontuberculous mycobacterial lung disease in Japan from 2012 to 2013. Ann Am Thorac Soc 2017;14:49-56.

9 Salzer HJ, Wassilew N, Köhler N, Olaru ID, Günther G, Herzmann C, Kalsdorf B, Sanchez-Carballo P, Terhalle E, Rolling T, Lange C, Heyckendorf J: Personalized medicine for chronic respiratory infectious diseases: tuberculosis, nontuberculous mycobacterial pulmonary diseases, and chronic pulmonary aspergillosis. Respiration 2016;92:199-214.

10 Shiraishi Y: Current status of nontuberculous mycobacterial surgery in Japan: analysis of data from the annual survey by the Japanese Association for Thoracic Surgery. Gen Thorac Cardiovasc Surg 2016;64:14-17.
11 Hahm CR, Park HY, Jeon K, Um SW, Suh GY, Chung MP, Kim H, Kwon OJ, Koh WJ: Solitary pulmonary nodules caused by Mycobacterium tuberculosis and Mycobacterium avium complex. Lung 2010;188:25-31.

12 Hara T, Kosaka N, Suzuki T, Kudo K, Niino $\mathrm{H}$ : Uptake rates of ${ }^{18} \mathrm{~F}$-fluorodeoxyglucose and ${ }^{11} \mathrm{C}$-choline in lung cancer and pulmonary tuberculosis: a positron emission tomography study. Chest 2003;124:893-901.

13 Kim IJ, Lee JS, Kim SJ, Kim YK, Jeong YJ, Jun S, Nam HY, Kim JS: Double-phase ${ }^{18}$ F-FDG PET-CT for determination of pulmonary tuberculoma activity. Eur J Nucl Med Mol Imaging 2008;35:808-814.

14 Higashi K, Ueda Y, Sakurai A, Mingwang X, Xu L, Murakami M, Seki H, Oguchi M, Taki S, Nambu Y, Tonami H, Katsuda S, Yamamoto I: Correlation of Glut-1 glucose transporter expression with [(18)F]FDG uptake in nonsmall cell lung cancer. Eur J Nucl Med 2000; 27:1778-1785.

15 Azov AG, Koch J, Hamilton-Dutoit SJ: Improved diagnosis of mycobacterial infections in formalin-fixed and paraffin-embedded sections with nested polymerase chain reaction. APMIS 2005;113:586-593.

16 Patel VK, Naik SK, Naidich DP, Travis WD, Weingarten JA, Lazzaro R, Gutterman DD, Wentowski C, Grosu HB, Raoof S: A practical algorithmic approach to the diagnosis and management of solitary pulmonary nodules: part 2: pretest probability and algorithm. Chest 2013;143:840-846.

17 Jeong YJ, Yi CA, Lee KS: Solitary pulmonary nodules detection, characterization, and guidance for further diagnostic workup and treatment. AJR Am J Roentgenol 2007;188:57-68.

18 Jeong YJ, Paeng JC, Nam HY, Lee JS, Lee SM, Yoo CG, Kim YW, Han SK, Yim JJ: ${ }^{18}$ F-FDG positron-emission tomography/computed tomography findings of radiographic lesions suggesting old healed tuberculosis. J Korean Med Sci 2014;29:386-391.

19 Fukunaga H, Murakami T, Gondo T, Sugi K, Ishihara T: Sensitivity of acid-fast staining for Mycobacterium tuberculosis in formalin-fixed tissue. Am J Respir Crit Care Med 2002;166: 994-997.

20 Hillemann D, Galle J, Vollmer E, Richter E: Real-time PCR assay for improved detection of Mycobacterium tuberculosis complex in paraffin-embedded tissues. Int J Tuberc Lung Dis 2006; 10:340-342.

21 Salian NV, Rish JA, Eisenach KD, Cave MD, Bates JH: Polymerase chain reaction to detect Mycobacterium tuberculosis in histologic specimens. Am J Respir Crit Care Med 1998; 158:1150-1155.
22 Walker DA, Taylor IK, Mitchell DM, Shaw $\mathrm{RJ}$ : Comparison of polymerase chain reaction amplification of two mycobacterial DNA sequences, IS6110 and the $65 \mathrm{kDa}$ antigen gene, in the diagnosis of tuberculosis. Thorax 1992; 47:690-694.

23 Ishige I, Usui Y, Takemura T, Eishi Y: Quantitative PCR of mycobacterial and propionibacterial DNA in lymph nodes of Japanese patients with sarcoidosis. Lancet 1999;354: 120-123.

24 Kim YN, Kim KM, Choi HN, Lee JH, Park HS, Jang KY, Moon WS, Kang MJ, Lee DG, Chung MJ: Clinical usefulness of PCR for differential diagnosis of tuberculosis and nontuberculous mycobacterial infection in paraffin-embedded lung tissues. J Mol Diagn 2015;17:597604

25 Hibiya K, Shigeto E, Iida K, Kaibai M, Higa F, Tateyama M, Fujita J: Distribution of mycobacterial antigen based on differences of histological characteristics in pulmonary $\mathrm{Myco}$ bacterium avium infectious diseases - consideration of the extent of surgical resection from the pathological standpoint. Pathol Res Pract 2012;208:53-58.

26 Hsiao CH, Lin YT, Lai CC, Hsueh PR: Clinicopathologic characteristics of nontuberculous mycobacterial lung disease in Taiwan. Diagn Microbiol Infect Dis 2010;68:228-235.

27 Schulz S, Cabras AD, Kremer M, Weirich G, Miethke T, Bosmuller HC, Hofler H, Werner $\mathrm{M}$, Fend F: Species identification of mycobacteria in paraffin-embedded tissues: frequent detection of nontuberculous mycobacteria. Mod Pathol 2005;18:274-282.

28 Griffith DE, Aksamit T, Brown-Elliott BA, Catanzaro A, Daley C, Gordin F, Holland SM, Horsburgh R, Huitt G, Iademarco MF, Iseman M, Olivier K, Ruoss S, von Reyn CF, Wallace RJ Jr, Winthrop K; ATS Mycobacterial Diseases Subcommittee; American Thoracic Society; Infectious Disease Society of America: An official ATS/IDSA statement: diagnosis, treatment, and prevention of nontuberculous mycobacterial diseases. Am J Respir Crit Care Med 2007;175:367-416.

29 Hsiao CH, Lin YT, Lai CC, Chou CH, Hsueh PR: Identification of nontuberculous mycobacterial infection by IS6110 and hsp65 gene analysis on lung tissues. Diagn Microbiol Infect Dis 2010;68:241-246.

30 Cook SM, Bartos RE, Pierson CL, Frank TS: Detection and characterization of atypical mycobacteria by the polymerase chain reaction. Diagn Mol Pathol 1994;3:53-58. 